\title{
Development of Petroleum Refining in Japan*
}

\author{
Shigeki Fukuba**
}

\section{Introduction}

Petroleum refining in Japan has a long history, but the production and refining of crude oil as an industry began in the middle of 19th century.

Since then, many refineries have been installed and expanded, and modern refining processes were introduced step by step to the refineries, and the crude unit refining capacity had reached to 80,000 barrels a day in 1944. However, 62 percent of refining capacity were lost by air-raids during World War II.

After the WVar, all of the refineries in the Pacific coast were closed by the order of occupation forces for several years, and only small refineries on the Japan Sea coast where the principal oil producing field existed were allowed to continue operation. The Pacific coast refineries were permitted to restart operation from January 1950.

Japanese refining companies were then forced to expand refining capacity to meet the significantly increasing demand for petroleum products. Existing refineries were expanded one by one, and new refineries were constructed on a large scale.

Modern refining processes were introduced to the refineries. Catalytic reforming units and kerosene and gas oil hydrotreating units were installed in alsmot all refineries. Catalytic cracking units were built to produce high octane gasoline in some refineries. Sweetening of straightrun naphtha was carried out extensively in the refineries. Solvent refining processes were installed to produce high viscosity index lubircating oils. Hydrocracking and fuel oil desulfurizing capacity is increasing in Japan.

Integration of refining processes is common to economize plant site, investment, labor and operating expense. A central control house serves for several process units. Intermediate tankage between process units are minimized. In some refineries inter-plant heat exchange system is carried out for heat economies.

Japan's refining capacity reached $2,330,900$

* Received January 18, 1968

** Nippon Oil Co., Ltd. barrels daily at the end of 1967 . The average capacity per refinery increased to 65,000 barrels daily nationwide and 80,000 barrels daily for those on the Pacific coast, which excludes the small refineries on the Japan Sea coast and in Hokkaido. The rapid expansion of refining capacity will continue to meet the ever increasing demand for petroleum products. Thus the capacity will be increased to approximately $3,300,000$ barrles daily by the end of 1970 .

\section{Crude and Vacuum Distillation}

All the earliest refineries operated by the batch system. Crude oil was charged to the vessel, and the products were distilled one by one by raising the temperature. An imported batch still was installed in 1879. Two Schulz high vacuum units were introduced in 1927. Although the batch stills survive even today in some refineries, continuous processes were introduced successively to Japan's refineries.

The Trumble process was installed by the Japanese Navy in its own refinery. Modern two stage unit, 2,500 barrels a day of crude and 1,250 barrels a day of vacuum, designed by FosterWheeler Corp., was installed in 1930. This unit was the first plant using pipe still and fractionation tower, essentially same as the present modern unit. Two Kellogg vacuum distillation units, 1,000 barrels a day each, were built in 1931. Bubble cap trays were provided in these fractionation towers, though rectangular trays were generally used in earlier ones. In 1932, the first continuous distillation unit was installed which was designed and constructed by our own engineering forces.

Crude and vacuum units were installed one after another to increase the amount of gasoline, fuel oil and lubricating oil, and the total capacity of crude units reached 57,000 barrels a day in private companies and 23,000 barrels a day of Army and Navy units in 1944.

After the World War II, most of the refineries in Japan were forced to suspend operation for several years, but they were rehabilitated and started 
operation after January 1950, and total capacity of crude units reached 68,000 ) barrels a day by the end of 1951.

Then, installation of crude units proceeded to meet the ever increasing demand for petroleum prodcuts. Total daily capacity of crude units reached 500,000 barrels in $1957,1,000,000$ barrels in 1961, and 2,000,000 barrels in 1965 .

On the other hand, vacuum units were installed step by step to obtain lubricating stocks and cracking stocks and total capacity of vacuum units reached 268,300 barrels daily by the end of 1967.

Capacities of crude and vacuum units are summarized on Table 1 .

Table 1. Crude and Vacuum Unit Capacity as of December 31, 1967

Crude Unit

\begin{tabular}{c|c|c}
\hline BPSD & No. of Unit & $\begin{array}{c}\text { Capacity, Barrels } \\
\text { per Stream Day }\end{array}$ \\
\hline less than 10,000 & 10 & 41,880 \\
$10,000-30,000$ & 26 & 440,020 \\
$30,000-50,000$ & 14 & 534,000 \\
$50,000-100,000$ & 15 & $1,000,000$ \\
over 100,000 & 3 & 315,000 \\
\hline Total & 68 & $2,330,900$ \\
\hline
\end{tabular}

Vacuum Unit

\begin{tabular}{c|c|c}
\hline BPSD & No. of Unit & $\begin{array}{c}\text { Capacity, Barrels } \\
\text { per Stream Day }\end{array}$ \\
\hline less than 5,000 & 21 & 43,400 \\
$5,000-10,000$ & 6 & 42,400 \\
$10,000-30,000$ & 9 & 148,500 \\
over 30,000 & 1 & 34,000 \\
\hline Total & 37 & 268,300 \\
\hline
\end{tabular}

In modern crude units, electrical desalters are now used to decrease the salt content of crude oil and to reduce corrosion in fractionation columns and heat exchangers.

When pipe stills were first built, down convection type heaters were commonly used, but these have now been almost completely replaced by other types. Upfired heaters developed by UOP, Lummus and others, which can operate at a high and well-regulated radiant absorption rate, and cylindrical circular radiant heaters which give uniform heat absorption rate and economical operation are more generally used in modern units.

Bubble cap trays were extensively used in crude and vacuum units. However, valve type trays and sieve trays which are more economical than bubble cap trays are used in modern units. For vacuum flashing units which are not necessariey need fractionation, side to side pan or shower trays are generally adopted and demisters are provided to prevent the entrainment of residuum. Glitsch grids are used in some modern units.

\section{Sweetening}

Sweetening processes have a long history in treating sour straightrun and cracked naphthas. Doctor, hypochlorite and copper chloride sweetening processes were carried out extensively from the 1930's in most of the refineries, and these sweetening processes are still used to treat straightrun naphtha in the refineries. Inhibitor sweetening is used to treat cracked naphtha.

The Merox process, developed by UOP, is an economical extraction and sweetening process and now it is quite common to treat sour straightrun naphtha, cracked naphtha and liquified petroleum gas. 17 units have been built and the total daily capacity of Merox unit reached 97, 500 barrels by the end of 1967.

\section{Octane Upgrading Facilities}

To increase the production of motor gasoline, thermal cracking units were installed extensively in the 1920's and 1930's. A 1,000 barrels a day Dubbs cracking unit was first installed in 1924 . Thereafter many thermal cracking processes, such as Jenkins, Cross and Gyro, were introduced into Japan refineries.

In the 1930's, Japanese Navy and Army needed to make high octane gasoline for aviation use. Thermal cracked naphtha was unstable and low in lead susceptibility, and Japanese Navy had installed hydrogenation units using nickel catalyst in 1936, then reformed the cracked naphtha and obtained 87 to 91 Motor octane aviation gasoline. UOP's iso-octane units were built in 1939 and later. Hydrocracking units using molybdenum catalyst were built in 1938 and later. Fixed bed catalytic cracking units using clay catalyst were built in 1939 and later. Most of these high octane gasoline manufacturing facilities were lost by the air rajds.

After the War, crude sources for import to Japan were changed from California to Middle East and octane number of straight run naphtha of Middle East crude was lower than that from California crude. On the other hand, higher octane gasoline was required by the increase of 
compression ratio of motor-car engines.

Catalytic reforming and catalytic cracking processes were very attractive because the quality of naphtha produced by these processes was better and the yield of naphtha from these processes was higher than that of the thermal processes.

Catalytic reforming and catalytic cracking produce 10 to 25 per cent of the feed of $\mathrm{C}_{3} \mathrm{~s}$ and $\mathrm{C}_{4}$ s. In Japan, domestic natural gas production is very small and the $C_{3}$ and $C_{4}$ fractions from catalytic processes contribute an essential source of liquified petroleum gas.

\section{Cracking}

Thermal cracking processes which were widely used to produce motor gasoline before the War have become obsolete and at present, a coker unit is only operating to make low sulfur coke from low sulfur residue.

Catalytic cracking processes developed during the war are of fundamental importance to the production of gasoline.

ES \& E's Model IV fluid catalytic cracking unit was introduced in 1955 , and then UOP and Shell's FCC units were constructed. For moving bed type, a Houdriflow catalytic cracking unit was installed.

Catalytic cracking is practiced on vacuum gas oil and deasphalted residue. 40 to 60 per cent naphtha from the feed are obtained, and 20 to 40 per cent catalytic cycle oil is rejected from the unit.

The large volume of $C_{3}$ and $C_{4}$ fraction, rich in olefinic gases, produced in catalytic cracking, made possible the utilization of these gases as alkylation, polymerization and petrochemicals feed stock, and liquified petroleum gas.

A $1,250 \mathrm{~B} / \mathrm{D}$ alkylation unit was installed in 1957 to make avaiation gasoline. A $220 \mathrm{~B} / \mathrm{D}$ polymerization unit was built in 1955 to increase

Table 2 Thermal and Catalytic Cracking Capacity as of December 31,1967

\begin{tabular}{lc:c}
\hline \multicolumn{1}{c}{ Process } & No. of Unit & $\begin{array}{c}\text { Capacity, Barrels } \\
\text { per Stream Day }\end{array}$ \\
\hline Viscosity Breaking & $1^{*}$ & 4,500 \\
Coking & 1 & 7,500 \\
Houdriflow & 1 & 3,500 \\
FCC (UOP) & 4 & 30,500 \\
FCC (ER \& E) & 2 & 28,900 \\
FCC (Shell) & 1 & 16,200 \\
\hline$\quad$ Total & 10 & 91,100 \\
\hline
\end{tabular}

*Not operating motor gasoline. Japan's first petrochemical plant produced isopropyl alcohol and acetone, and the feed stock was propylene produced from catalytic cracking unit.

The present capacities of cracking processes are shown in Table 2.

\section{Catalytic Reforming}

Platforming and other catalytic reforming processes were given much attention by Japanese refining companies after the War, because they were facing the need to improve the antiknock quality of motor gasoline to meet motor cars engine performance.

The first two Platforming units were built at the end of 1953, and many were followed. Heavy straightrun naphtha from Middle East crude is very low in Octane number and the adoption of catalytic reforming is the only way to improve the octane rating of heavy straightrun naphtha, this process is extensively appllied by Japan's refining companies. At present 26 refineries of 36 Japan's total refineries have one or more catalytic reforming units. The present capacities of catalytic reforming units are shown in Table 3 .

Table 3 Catalytic Reforming Capacity ${ }^{-}$(Exclude Aromatics Production Units) as of December 31, 1967

\begin{tabular}{l|c|c}
\hline \multicolumn{1}{c|}{ Process } & No. of Unit & \multicolumn{2}{c}{$\begin{array}{c}\text { Capacity, Barrels } \\
\text { per Stream Day }\end{array}$} \\
\hline Platforming & $\ldots$ & 179,400 \\
Powerforming & 26 & 36,600 \\
Shell Process & 3 & 4,800 \\
Houdriforming & 1 & 11,000 \\
\hline Total & 2 & 231,800 \\
\hline
\end{tabular}

At first, octane number of reformate was 80 to 85 clear by Research method, but now 95 to 97 clear reformate is obtained by improvement of catalyst and the development of reformer design.

Catalytic reforming processes produce an excess hydrogen of 300 to 1,500 cubic feet per barrel charge. This hydrogen is now extensively used for hydrogen treating in the refineries.

The reformate obtained under severe conditions contains large quantities of aromatics, and benzene, toluene and xylene are recovered as chemicals.

\section{Hydrogen Treating and Hydrocracking}

Hydrogen treating and hydrocracking as practiced toady are relatively new, although such 
processes were used in Japan to make aviation gasoline prior to World War II. The modern hydrogen treating process was developed in the middle 1950's, and modern hydrocracking process has come onstream quite recently in Japan.

\section{Hydrogen Treating of Light Distillate}

Lp to the 1950's treatment of kerosene, where necessary, had been carried out primarily to improve odor and color. Acid treating or sweetening processes were used to extract objectionable sulfur compounds or convert them to less corrosive and less odoriferous forms. However, consumers demand for sulfur-free products with improved burning characteristics increased. For diesel gas oil, desulfurization was necessary when high sulfur crudes were mainly imported after 1950. In catalytic reforming, where platinum catalyst is generally used, sulfur and nitrogen in the feed stock were poison to the catalyst.

Hydrogen treating reaction is a selective hydrogenation which converts organic compounds of sulfur, nitrogen and oxygen into hydrocarbons and removable hydrogen sulfide, ammonia and water. Then naphtha pretreating of catalytic reformers resulted in longer life of the expensive platinum catalyst. For kerosene burning characteristics, color and odor were improved and for gas oil, approximately 90 percent of sulfur was easily removed and color was improved by hydrogen treating.

With the installation of catalytic reformers, refineries had the cheap hydrogen needed to solve the desulfurization problem. In the same period, many hydrogen treating processes were established with the development of cobalt molybdenum catalyst.

Platforming unit provided with naphtha pretreatment was built in 1958. Two Unifiners were installed to desulfurize kerosene and diesel gas oil in 1957. Many followed, and hydrogen treating is now extensively used for naphtha pretreating of catalytic reformers, kerosene and diesel gas oil. Hydrogen treating is used to treat straightrun naptha blended for gasoline and jet fuel in some refineries. Removing sulfur from naphtha improves the lead susceptibility. The present capacities of naphtha and middle distillate hydrotreating processes are shown in Table 4 . Of these capacities 228,700 barrels daily are used for straightrun naphtha and 298,950 barrels daily are used for middle distillates.
Table 4 Naphtha, Kerosene and Gas Oil Hydrotreating Capacity as of December 31, 1967

\begin{tabular}{l|c|c}
\hline \multicolumn{1}{c|}{ Process } & No. of Unit & $\begin{array}{c}\text { Capacity Barrels } \\
\text { per Stream Day }\end{array}$ \\
\hline Unifining & 43 & 299,050 \\
Shell & 8 & 99,000 \\
Hydrofining (ER \& E) & 11 & 111,600 \\
Houdry & 2 & 11,000 \\
Houdry-Daikyo & 1 & 7,000 \\
\hline \multicolumn{1}{c|}{ Total } & 65 & 527,650 \\
\hline
\end{tabular}

In addition to reactions which remove contaminants, the process selectively hydrogenates olefins to more stable compounds while minimizing saturation of aromatics. Hydrogen treating of by-product naphtha from ethylene cracking is now commonly carried out and valuable aromatics and gasoline blending stock are recovered in petrochemical plants.

\section{Hydrocracking}

Isomax and other hydrocracking processes were developed essentially to convert undesirable high boiling hydrocarbons into salable lower molecular weight of high value. These processes are intended to increase high octane gasoline from light and heavy gas oil in the United States. However, in Japan, hydrocracking processes were thought attractive to make liquified petroleum gas and distillate fuel rather than to make gasoline.

The first Isomax unit was installed to maximize middle distillate from vacuum gas oil in 1965. Then three Isomax units were built to produce liquified petroleum gas from naphtha. By the end of 1967, four hydrocracking units, all Isomax, with a total capacity of 21,500 barrels daily were on stream.

\section{Hydrodesulfurization of Residual Fuel Oil}

Recently, in Japan, reduction of the sulfur content in residual fuel oil has become an urgent need, in order to reduce air pollution due to sulfur dioxide in flue gas.

However, the demand for residual fuel oil accounts for 60 percent of the total petroleum products in Japan, and the importation of low sulfur crude oil and low sulfur fuel oil is limited. Therefore, desulfurization of fuel oil is becoming a very important problem.

Biochemical and metal oxide processes are reported to remove sulfur compounds from residual fuel oil, but these processes are not developed commercially. Hydrodesulfurization 
process is considered to be the only available way to solve the problem.

Chevron Research Corp. and Universal Oil Products Company announced that the Isomax process, originally developed as a hydrocracking process, can be used to hydrodesulfurize vacuum gas oil and residual oil. Also the HDS process of Gulf Research Corp. and H-Oil process of Hydrocarbon Research Inc. \& Cities Service Research \& Development Company are reported as hydrodesulfurization processes for residual oil.

Most refining companies in Japan have shown keen interest, and have studied to evaluate these processes. A 40,000 B/D UOP RCD Isomax unit was installed to desulfurize atmospheric residuum of high sulfur crude in October 1967. CRC's Isomax and others are now constructing or planning to desulfurize vacuum gas oil.

\section{Hydrogen Manufacturing}

Hydrocracking of gas oil or hydrodesulfurization of residual fuel oil processes require large quantities of hydrogen, and installation of hydrogen manufacturing unit is generally unavoidable.

In Japan, three hydrogen units using steam reforming processes have been installed, accompanying the installation of hydrocracking or hydrodesulfurization units. Refinery gas or naphtha 15 used as feed stock. 95 to 97 percent purity hydrogen are produced at 300 to 400 psig. Total capacities of $71,500,000$ SCFD are on stream by the end of 1967.

\section{Sulfur Recovery}

Hydrogen sulfide produced by hydrodesulfurization or catalytic cracking process can be used as refinery fuel gas. However, sulfur dioxide contained in flue gas causes air pollution, so sulfur must be recovered except for minor quantities of hydrogen sulfide and the location is in the country side.

In some refineries, hydrogen sulfide is absorbed in caustic soda solution and is converted to sodium hydrosulfide solution. However, the price of sodium hydrosulfide solution is very low, and this process is limited to the case where waste soda is available and/or recovered hydrogen sulfide is very small. At present Claus type sulfur recovery process is extensively used in the refineries. Elementary sulfur is recovered by the partial combustion of hydrogen sulfide, and 53,664 tons sulfur were recovered in 1966. Fourteen plants with a total capacity of 605.5 tons daily are in operation at the end of 1967.

\section{Lubricating Oil}

In the early years, lubricating oils such as spindle oil, machine oil and motor oil were mainly produced from naphthenic crudes, domestic or imported. The vacuum distillates from these crudes were treated with acid, filtered through clay by percolation, or contacted with clay at a high temperature.

The acid treatment of lubricating oil stocks was generally conducted in batch agitators. However, use of centrifuges was promoted to take advantage of the smaller amount of acid dosage, continuous operation, and the ease of control of operating variables.

The most common finishing method was the clay contacting process. Contacting was practiced on sour oil and neutralized oil. These conventional acid treating and clay processes are old but still used in many refineries.

Before the War, most of the high grade lubricating oils were imported, but it became necessary to make high viscosity index oils for aviation and locomotive uses. Solvent refining processes developed in the 1930's in the United States and others were paid attention to by Japanese oil companies.

Three major substances are usually considered in eliminating the undesirable constituents from crude lube oils: asphaltic substances, wax and low viscosity index oils. The ability of light hydrocarbon to precipitate asphalt from residual stocks had been studied as early as 1920 . Propane had been chosen as the proper solvent for commercial use. Countercurrent extraction with solvent such as furfural and phenol in multiple batch operations or in counter-flow towers was applied to the oil to separate low viscosity index naphthenic oil. Conventional dewaxing process were carried out in some refineries. Wax distillates were chilled and filtered and waxfree oils were recovered. However, this process could be applied only for the pressable light distillates, and heavy lubricating oils were not made. Solvent dewaxing can remove wax of either crystalline or amorphous type. With acetonebenzol process and propane process the separated wax can be easily removed by filtration, while with the Bari-Sol process, in which ethylene 
dichloride and benzol were used as solvent, this separation must be accomplished by centrifuging.

Two furfural extraction units were built in 1940 and in 1943 respectively. Two solvent refining units using mixed solvent of phenol and cresol were bult in 1940 and 1942. Two Duo-Sol units were built in 1940. Two propane deasphalting units were built in 1940 and 1943. Four Bari-Sol dewaxing units were built, one in 1938, and three in 1939. Three solvent dewaxing units using acetone and benzol were built, one in 1939, and two in 1943. A propane dewaxing unit was built in 1940 .

After the War, crude oils were mainly imported from Niddle East and Sumatra. These crudes are paraffinic or intermediate base, and contain appreciable quantities of wax. Thus, installation of solvent dewaxing units were carried out extensively. MEK dewaxing process was adopted extensively, while a propane dewaxing unit was also installed.

Requirement for high grade, high viscosity index oils had been increasing very much corresponding the development of the gasoline engine, diesel engine, steam turbine, compressor and etc., and furfural and phenol extraction units were installed. Propane deasphalting units were built to make bright stock and cylinder stock. The capacities of solvent refining processes are shown in Table 5.

Table 5 Solvent Refining Capacity as of December 31, 1967

\begin{tabular}{l|c|c}
\hline \multicolumn{1}{c|}{ Process } & No. of Unit & $\begin{array}{c}\text { Capacity, Barrels } \\
\text { per Stream Day }\end{array}$ \\
\hline Operating & & \\
Furfural Extraction & 9 & 12,990 \\
Phenol Extraction & 1 & 2,600 \\
Duo-Sol & 2 & 2,200 \\
Propane Deasphalting & 2 & 4,760 \\
MEK Dewaxing & 11 & 14,549 \\
Propane Dewaxing & 1 & 2,200 \\
Bari-Sol Dewaxing & 1 & 500 \\
Under Construction & & 18,400 \\
Furfural Extraction & 3 & 16,500 \\
Propane Deasphalting & 3 & 11,500 \\
MEK Dewaxing & 3 & 1968. \\
\hline
\end{tabular}

*These units will be completed March 1968.

Clay contacting is now generally used to finish lubricating oils. However, hydrogen finishing process are intended to replace clay processes because of the following reasons:

1) Lower construction and operating cost.

2) Higher product yield

3) No waste (In case of clay treating, spent clay has to be disposed of)

A 3,000 B/D Hydrofining unit was built in 1964, and two hydrogen finishing units are now under construction.

Requirements for solvent refined, high viscosity index oils produced from paraffinic crudes are increasing rapidly, though specialty products, such as transformer oils, refrigerator oils and process oils blended with synthetic rubber are produced from naphthenic crudes.

Various additives are added to the lubricating oil base stocks to improve performance. Detergents, oxidation inhibitors, rust inhibitors, viscosity index improvers and pour point depressants are commonly used in accordance with the service of lubricating oils.

\section{Paraffin Wax}

Pressing and sweating was used for removing and producing wax from wax distillates in 1930's and 1940's. Wax is crystallized by chilling of the oil and is removed in filter presses as slack wax. The latter is melted, then frozen into a cake, and heated slowly. In this sweating operation, the oil that adheres to the wax drains from the cake.

After the War, solvent dewaxing processes, predominantly MEK process, were used to dewax wax distillates, instead of pressing process, though the latter process is still used in some refineries. Slack wax containing 2 to 15 percent oil is produced by solvent dewaxing process. Upon sweating, a scale wax containing less than 0.5 percent oil is obtained. Acid treating and clay finishing follow to improve the odor, color and stability. 64,000 metric tons of wax were produced in 1966.

\section{Development in Future Energy Situation}

In the last decade, Japan's rapid economic growth has resulted in a tremendous increase in energy consumption. Currently, energy consumption has reached $135 \times 10^{13} \mathrm{Kcal}$ in fiscal 1965, which is more than 2.8 times greater than that of fiscal 1955 . 78 percent of the total incremental energy from 1955 to 1965 was supplied by petroleum.

A preliminary forecast of energy supply in Japan, which was made public by the Energy Research Council in February 1967 shows that the total energy supply will amount to $241 \times 10^{13}$ 
Kcal in fiscal $1970,340 \times 10^{13} \mathrm{Kcal}$ in fiscal $197 j$ and $598 \times 10^{13} \mathrm{Kcal}$ in fiscal 1985 ; petroleum, excluding LPG, will account for approximately 67 percent in fiscal 1970, 73 percent in fiscal 1975 and 75 percent in fiscal 1985 . In other words, demand for petroleum products will be tremendously increased to 172 million $\mathrm{Kl}$ in fiscal 1970, 261 million $\mathrm{Kl}$ in fiscal 1975 and 468 million $\mathrm{Kl}$ in fiscal 1985.

\section{Product Pattern}

The product demand pattern has changed considerably in the last decade. Gasoline declined from 25.2 percent in fiscal 1955 to 13.3 percent in fiscal 1965 of the total products demand, while fuel oil increased from 55.0 percent in fiscal 1955 to 59.4 percent in fiscal 1965. However, naphtha, which accounted for 2.8 percent of the total product demand in fiscal 1960, increased to 9.7 percent in fiscal 1965. As for jet fuel, kerosene and gas oil, their share in the products demand showed no substantial change. The production and demand of petroleum products are shown in Table 6 and Figure 1.

Table 6 Production of Petroleum Products in Fiscal 1966

\begin{tabular}{l|r|r}
\hline \multicolumn{1}{c|}{ Product } & $\begin{array}{c}\text { Production in } \\
1,000 \text { Kiloliters }\end{array}$ & Percent \\
\hline Aviation Gasoline & 92 & 0.1 \\
Moter Gasoline & 12,561 & 12.2 \\
Industrial Gasoline & 266 & 0.3 \\
Naphtha & 9,527 & 9.2 \\
Jet Fuel & 1,720 & 1.7 \\
Kerosene & 7,085 & 6.9 \\
Diesel Gas Oil & 7,355 & 7.1 \\
Fuel Oil & 57,395 & 55.6 \\
Lubricating Oil & 1,366 & 1.3 \\
Paraffin Wax & 104 & 0.1 \\
Asphalt & 1,883 & 1.8 \\
Liquified Petroleum Gas & 3,667 & 3.6 \\
Others & 174 & 0.1 \\
\hline \multicolumn{1}{c}{ Total } & 103,195 & 100.0 \\
\hline
\end{tabular}

In the future, the increase in demand for naphtha will continue to be predominant for the production of ethylene, aromatics, ammonia and town gas. The demand for motor gasoline, kerosene, gas oil and fuel oil will continue to increase at a comparatively high rate, but the share in the total product demand will be basically unchanged.

\section{Properties of Petroleum Products}

At present, motor gasoline has 97 to 100 Research octane for premium grade and 88 to 91

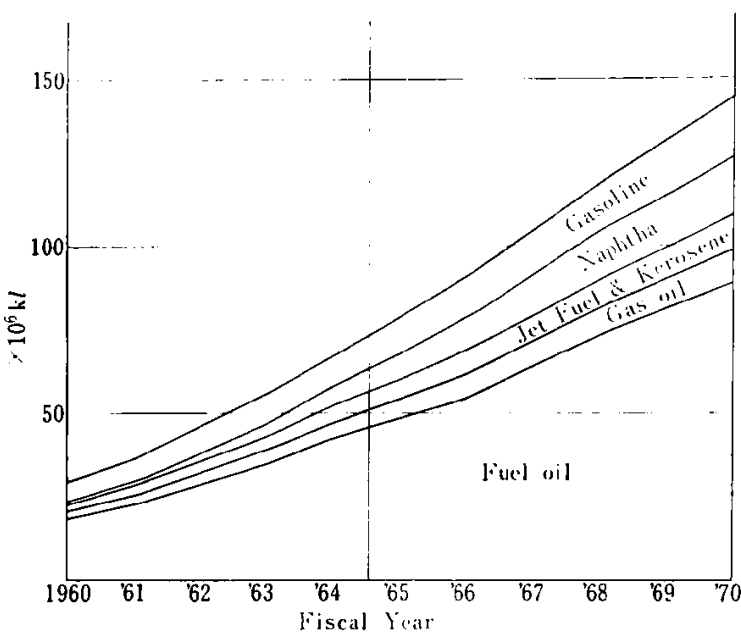

Fig. 1. Actual and Estimated Domestic Demand for Fuel Type Products

for regular grade. Research octane number of motor gasoline will gradually rise to 100 to 101 octane for premium grade and 94 to 95 octane for regular grade in a few years, accompanied by the increase of compression ratio of automotive engine.

As the compression ratio of automobile engine is increased to acquire more power, the engine has a greater tendency to knock at high speeds.

The Motor octane rating of gasoline is specifically related to road octane at high speeds.

Catalytic reforming units are now in use to produce high octane gasoline in almost all refineries. Catalytic cracking units also contribute to increase octane number in some refineries. However, catalytic reformate and cracked naphtha have high sensitivity, i.e. the difference between Research and Motor octane is high. Alkylate and hydrocrackate have not only high Research octane but high Motor octane, and installation of alkylation units and/or hydrocracking units will be considered in the future to make low sensitivity gasoline.

Jet A-1, JP-4, and JP-5 are mainly used for jet fuel. Properties required for jumbo jet and supersonic transport are not clear now, but the properties may not be too different from the present ones, though the thermal stability, vapor pressure, specific heat and burning quality will probably be improved.

Properties of kerosene and diesel gas oil will be essentially same as at present.

For fuel oils, reduction of sulfur content is becoming an important problem in reducing air pollution. Target of sulfur content in fuel oil was shown by the Energy Research Council in 
February 1967 that it should be reduced to $\mathbf{1 . 7}$ percent in 1969 and after in inordinately air polluted area. The target would be revised and lower sulfur content fuel oil would be required in future with the development of desulfurization process and extent of pollution

\section{Prevention of Public Nuisance}

Pollution of air and water have become serious nationwide in Japan.

Sulfur recovery units have been installed to decrease the content of sulfur dioxide in flue gas in the refineries. High stacks as tall as 100 to 130 meters are commonly constructed in industrial areas to lower the concentration of sulfur dioxide in the atmosphere. Removal of sulfur dioxide from flue gas are now conducted experimentally in some electric power plants.

Reducing the sulfur content in fuel oil is essential in decreasing air pollution. However, the desulfurization of fuel oil is more expensive than that of lighter stock, because the content of metallic compounds and carbonaceous materials are high and they affect adversely the catalyst. Therefore, large sums of initial investment and operating cost are necessary to reduce the sulfur content of fuel oil.

Japanese petroleum refining companies, Resources Research Institute and Government Chemical Industrial Research Institute, Tokyo are now studying to find more economical processes and more effective catalysts for fixed bed and ebullating bed type hydrodesulfurization processes for high sulfur residue. The Japanese Government is promoting the development of processes for the removal of sulfur djoxide from flue gas and the hydrodesulfurization of high sulfur residue in its "Major Development Projects" program.

Recently, pollution ot the sea by oil has become serious accompanying the rapid growth in movement of crude and petroleum product.

In 1967, the Japanese Government ratified the International Convention for the Prevention of Pollution of the Sea by Oil. The main requirements as regards the oil and tanker industries are to prohibit discharge of persistent oily ballast containing more than $100 \mathrm{ppm}$ of oil within 50 nautical miles from coastlines.

In order to achieve an effective, quick and voluntary solution to the problem, shore slop facilities to treat ballast water discharged from tankers are being constructed on six major oil loading ports beginning 1967, and further construction of additional six facilities will be started in 1968.

On the other hand, major oil companies are now proceeding "Load-on-top" system for their crude tankers to restrict pollution of the sea. Under the load-on top system tank washings are collected in a slop tank and allowed to settle. The settled clean water is pumped into the sea. On arrival at the loading port, the next cargo is loaded on top of the retained oily ballast in the slop tank. The cargo with oil ballast is discharged as normal at the unloading refineries. This system can be operated with almost all crude oils.

\section{Refineries of the Future}

Expansion of refineries and installation of new refineries must continue to meet the ever increasing tremendous demand for petroleum products.

By the Petroleum Industry Law in Japan, permission of the Minister of International Trade and Industry is required to make new installations, expansions to, or remodelling of crude units, vacuum units and octane upgrading facilities.

In August 1967, installation of approximately 740,000 barrels daily crude units was newly approved, and the refining capacity will be increased to $2,790,900$ barrels daily by the end of $1968,3,047,900$ barrels daily by the end of 1969 , and $3,317,900$ barrels daily by the end of 1970 .

Furthermore, crude thruput will have to be increased to approximately $4,5(), 000$ barrles daily in 1975 and $8,200,000$ barrels daily in 1985 to meet the demand of petroleum products.

To decrease the sulfur content in fuel oil, now almost all of the refining companies are planning the installation of fuel oil desulfurization units. Most of them are considering desulfurizgation of vacuum gas oil, and some are of atmospheric residue. It is estimated that the capacity of fue] oil desulfurization units will reach approximately 400,000 barrels daily in a few years.

At present, more than half of the total refineries have 50,000 to 180,000 barrels daily crude refining capacity, but refineries having 200,000 to 300,000 barrels daily crude refining capacity will be come in the next decade. Maximum daily thruput of major process units are 110,000 barrels for crude unit, 34,000 barrels for vacuum unit, 23,300 barrels for fluid catalytic cracker, and 22,800 barrels for 
catalytic reformer. However, larger capacities process units will be installed corresponding to the scale up of refineries.

Crude unit, catalytic reformer, kerosene hydrotreater, gas oil hydrodesulfurizer, heavy fuel stock (vacuum gas oil or residual oil) hydrodesulfurizer, hydrogen manufacturing unit and sulfur recovery unit will be essential in the new refineries. Catalytic cracker and/or hydrocracker will be built to cover the shortage of motor gasoline, because most of the straightrun naphtha will be supplied to the petrochemicals and fertilizer company. 